\title{
The role of systems analysis as an instrument in policy making and resource management
}

\author{
R. RABBINGE 1,2 , P.A. LEFFELAAR 2 and H.C. VAN LATESTEIJN1 \\ I Netherlands Scientific Council for Government Policy, P.O Box 20004, 2500 EA, The Hague, \\ The Netherlands \\ 2 Dept. of Theoretical Production Ecology, P.O. Box 430, 6700 AK Wageningen, The Netherlands
}

Key words: aggregation level, decision making, interdisciplinarity, land evaluation, natural resource management, policy making, priority setting, simulation models, systems approach

\section{Introduction}

The use of systems approaches in agricultural research has increased considerably during the last decades. Within the field of systems approaches, scientists around the world have developed several different types of models. Conceptual, comprehensive, and summary models function to integrate multidisciplinary research at various aggregation levels. Some of these models merely describe biological and agricultural systems to generate an insight into the system itself. Summary models, based on these explanatory, comprehensive models, may help in priority setting in research. Summary models are also used in quantitative land evaluation, and may structure resource management research at high aggregation levels. Other models may help policy makers in their strategic and tactical decision making at various levels of integration and aggregation.

This paper will illustrate each of these applications of systems approaches and their application for the various purposes. We will describe some of the prerequisites and limitations of the various models and show the usefulness of systems approaches by giving some examples of appropriate use.

\section{Systems approaches in agroecosystems}

Agricultural research as well as biological research aim at understanding living production systems. Biological research aims to describe and understand basic processes, while agricultural research tries to gain insight into the ways various characteristics at the crop, cropping-system, or farming-systems level may be manipulated to improve production, both quantitatively and qualitatively. Agricultural systems are too complex to be investigated as a whole. Research therefore distinguishes between aggregation levels (e.g., region, farm, cropping system, crop level), subsystems (e.g., soil, plant, pathosystems), and subprocesses (e.g., transport processes, photosynthesis, energy balance, growth and decrease of populations) (figure 1). Processes and systems can be studied by analyzing and formulating their interactions and relationships with the environment in mathematical formulas (systems 
analysis). Processes may be integrated by simulation models (systems synthesis), and the consequences of changes in the external conditions by human activity may be evaluated with integrative tools (systems evaluation). Subsystems, processes, and subprocesses usually operate on much smaller time and spatial scales than the system as a whole. The levels of aggregation at which subsystems operate may be distinguished with time coefficients as a yardstick. As a rule, the time coefficient rises with the aggregation level. Subcellular processes have time coefficients smaller than milliseconds, cells are recorded in the order of seconds, plants react in hours, crops in days or weeks, agroecosystems in months, and ecosystems have reaction times in the order of years (figure 2). The levels of aggregation with respect to their characteristic times may be distinguished with steps of 10 up to 100. Each aggregation level has underlying subsystems or processes that may be combined or even integrated to better understand the functioning of the higher aggregation level. The same hierarchical relation holds for spatial scales. Figures 1 and 2 illustrate the various biological processes that operate in plants and crops and the various disciplines involved in the study of these systems.

\section{Constructing simulation models for systems research}

Ten steps, divided over three phases, may be distinguished in simulation for scientific and applied purposes (table 1) (Rabbinge and De Wit 1989).

The first phase, the conceptual phase, comprises a clear description of the system, its various elements, and its relationship with the environment in qualitative terms. The second phase concerns the comprehensive modelling phase. Next, the evaluation and application phase, the third phase, comprises various steps and results in decision rules (when necessary) or forecasting models.

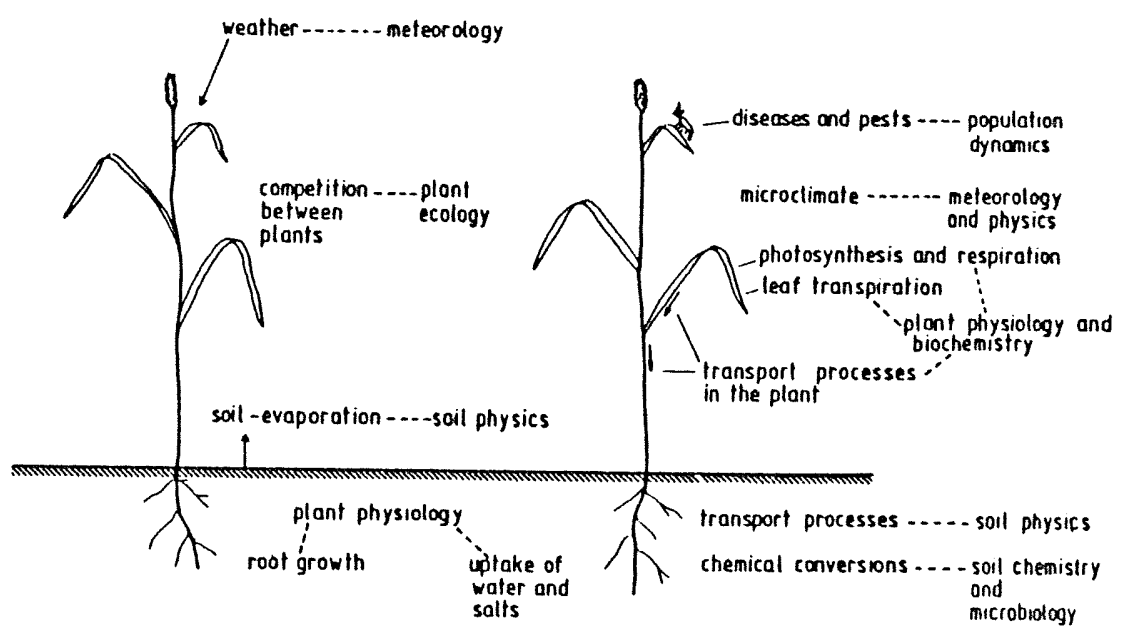

Figure 1. A crop system and some subsystems and processes that may be distinguished for its study (Source: De Wit 1982) 
time coeflicient (years)

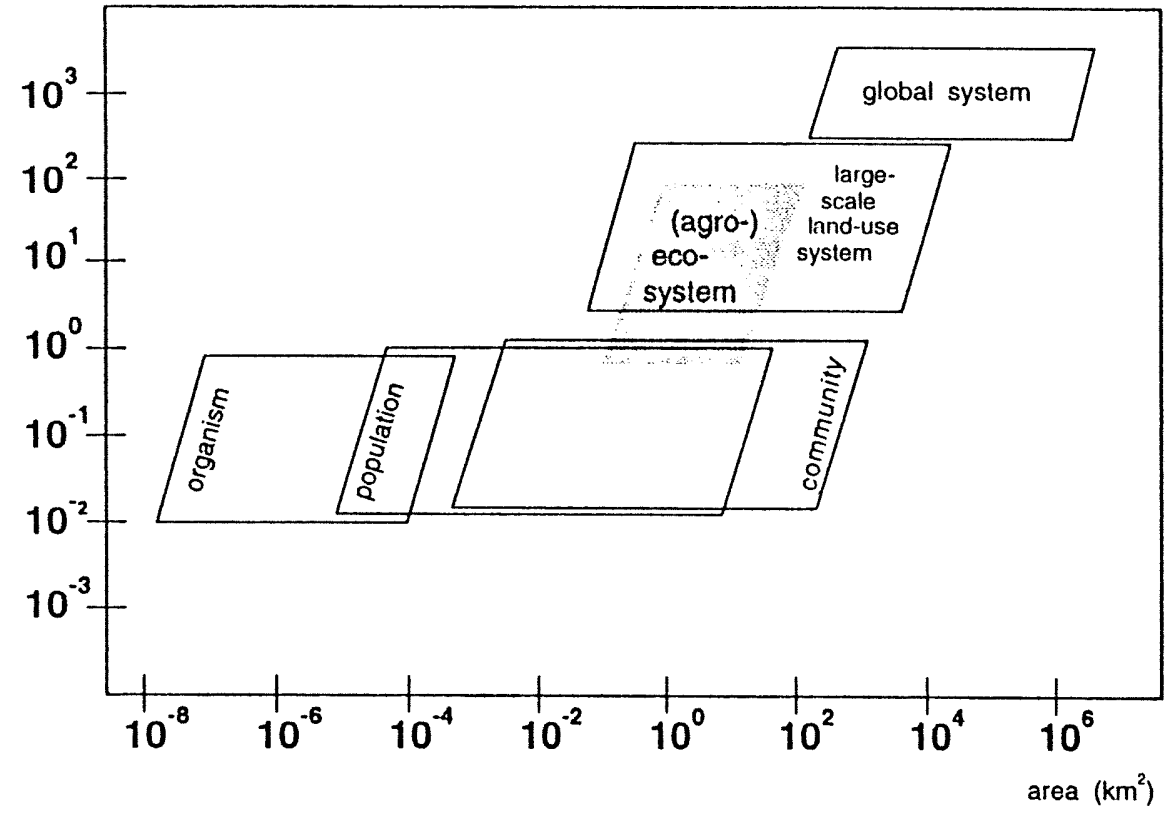

Figure 2. Spatial and temporal scales that may be distinguished in production ecological studies (Source: Rabbinge et al. 1993)

Table 1. Steps in model building

\section{CONCEPTUAL PHASE}

I. Formulation of objectives

2. Definition of the limits of the system

3. Conceptualization of the system

\section{COMPREHENSIVE MODELLING PHASE}

4. Quantification of input relations

5. Model construction

6. Verification of the model

EVALUATION AND APPLICATION PHASE

7. Validation

8. Sensitivity analysis, feasibility studies

9. Simplification, summary models

10. Formulation decision rules or forecasting models

(Source: Rabbinge and De Wit 1989) 
The conceptual phase starts with defining clearly the objectives of the study. After the objectives have been defined, the limits of the system in time and space may be described. Then the various state and rate variables and their relations with the environment are identified.

The comprehensive modelling phase assesses the input relations in quantitative terms. This requires much information from literature studies and experiments on the process and/or subsystem levels. The input relations should always be based on information from the next-higher level. The modelling phase comprises the actual construction of a simulation model. Then verification takes place; the model's behavior is compared with the expected behavior.

When expected behavior and model behavior correspond, and after the time coefficients have been checked and the input relations screened, the simulation model is ready for the third phase. Since verification in phase two is a technical activity, it does not compare the behavior of the model with the behavior of the actual systems under various circumstances. In a validation, the model's behavior as a whole (on the level of the system being modelled) is compared with the experimental behavior of the system under study, at various places and under various circumstances. Thus, validation takes place at the systems level.

Sometimes, a lack of data prevents validation. In such a case, a sensitivity analysis may nevertheless show the relative importance of various variables. First, a sensitivity analysis of the structure of the model tests the hypothesis and correctness of the state variables chosen. Second, a parameter sensitivity analysis tests the consequences of changes of (some of the input relations. If the model validation and sensitivity analysis produce a reliable model, a feasibility study may follow. Next, the possibilities of the system are explored under circumstances that differ considerably from those used during model building. However, it is important that these circumstances stay within the limits of the structure, the parameters, and the time and spatial scales of the model; if they do not, results may be nonsensical.

The results of the sensitivity analysis may produce a simplified model, which may result in summary models that grasp the main features of the system. These summary models may be used in the tenth and last step to formulate decision rules or forecasting models. Examples of this may be found in population dynamical studies (Van Roermund and Van Lenteren 1994) and crop protection (Rabbinge and Rijsdijk 1983).

Many studies, however, end after step six. Steps are also sometimes taken in a different order. An iterative heuristic approach is often followed.

\section{Systems research aimed at gaining understanding}

Simulation models are used to bridge or connect two or at the most three aggregation levels (De Wit 1968). Quantitative knowledge at the underlying level is combined and used to understand the behavior of a system as an entity. By comparing model behavior with the behavior of the real world, e.g. by experimental research, hypotheses may be tested, thus enhancing the understanding of these systerns. 
The level of detail depends on the objectives of the study. For example, studies on soil aeration and denitrification (Leffelaar 1986, 1988) tried to understand the causes and results of denitrification in partially water-saturated soil. This objective requires an explanatory simulation model, interconnecting spatial and temporal scales of the organisms and transport processes involved. The spatial scale is in the order of one to ten centimeters, which is the level of soil aggregates, whereas the oxygen concentration varies from 21 to 0 percent within a few millimeters when the soil is water saturated. The time coefficients for the biological processes involved, such as respiration and denitrification, and for the physical processes, such as water flow and gas diffusion, ranged from 24 hours to 60 seconds. Therefore, a better quantitative understanding of this soil ecological system requires simulation models that use time steps of seconds and spatial units of millimeters. The information gathered through these detailed studies can then be summarized in new relationships and used in models at higher integration levels.

Another example of a model study aiming at explanation is the population dynamics of the larch bud moth (Zeiraphera diniana) in the Ober Engadin (a mountain valley in Southeast Switzerland) (Van den Bos and Rabbinge 1976). For more than 120 years, the larch bud moth has shown a regular population density cycle with a frequency of nine years. There is a 3000 -fold difference between the maximum and minimum densities. The time coefficient in this system is in the order of days, while the spatial unit, the Ober Engadin, measures 40,000 ) ha. The appropriate time and spatial scales in this simulation model are therefore days, while the Ober Engadin is considered as an entity. Data for the densities of the larch bud moth were monitored by direct sampling during the last three decades and by observing tree growing rings during the period 1850-1950.

Although we could give more examples of different time and spatial scales, these two examples show the need to specify the objectives and the time and spatial boundaries of systems in explanatory studies that use systems approaches.

\section{Systems approaches aimed at building a research agenda}

Asking the right questions and doing the appropriate experiments are the most difficult parts of research. Experiments are expensive, time consuming, and pain staking, and should therefore be limited. Some pointers may help, however, such as "experiment only if you can't obtain your information in any other way", and "use an experiment only to answer an explicit question".

Suggestions such as these may generally help limit the number of experiments, but they do not help set priorities. Through feasibility and sensitivity studies, model calculations may help highlight elements of the process that need further elaboration. This is illustrated in a study on the effect of growth-reducing factors by Bastiaans (1993). Using comprehensive simulation models and summary models, Bastiaans showed the relative contribution of various growth-reducing factors on the growth and production of rice. Through this analysis, research priorities can be set in two steps (table 2). First, it appears that the relative contribution of the leaf folders is 
Table 2. Simulated reduction in grain uield $\left(\mathrm{Mg} \mathrm{ha}^{-1}\right)$ for rice crops infected by leaf blast (Pyricularia oryzae) and contribution of the various damage mechanisms. Primary effects on radiation interception (RI) are caused by lesion coverage and leaf senescence. The contribution of the various primary effects on radiation use efficiency (RUE) were determined separately. Simulations were made for leaf blast cpidemics with a maximum disease severity of 0.10 and various onset times (15, 29, and 43 days after transplanting (DAT). Bracketed numbers represent relative contributions.

\begin{tabular}{|c|c|c|c|}
\hline & \multicolumn{3}{|c|}{ Onset time of the epidemic } \\
\hline & $15 \mathrm{DAT}$ & 29 DAT & $43 \mathrm{DAT}$ \\
\hline Total reduction due to leaf blast & $1.8(1.00)$ & $2.8(1.00)$ & $3.3(1.00)$ \\
\hline \multirow[t]{2}{*}{ Reduction due to primary effects on RI } & $0.9(0.50)$ & $1.7(0.63)$ & $2.3(0.69)$ \\
\hline & - & - & - \\
\hline Reduction due to primary effects on RUE & $0.9(0.50)$ & $1.1(0.37)$ & $1.0(0.31)$ \\
\hline \multicolumn{4}{|c|}{ Contribution of the various primary effects on RUE: } \\
\hline - Reduced leaf photosynthetic rate & $53 \%$ & $48 \%$ & $44 \%$ \\
\hline - Increased leaf maintenance respiration & $3 \%$ & $4 \%$ & $3 \%$ \\
\hline - Assimilate uptake by the pathogen & $44 \%$ & $48 \%$ & $53 \%$ \\
\hline
\end{tabular}

(Source: Bastiaans 1993)

almost zero and that of the leaf blast is extremely high. Research should therefore be directed to the latter, while secondary pests such as rice borers should receive much lower emphasis. Second, the most important damage mechanism can be assessed. The relative contribution of maintenance respiration is negligible, but assimilate uptake and reduced leaf photosynthetic rate is equally important. Thus, research on leaf photosynthesis may be necessary.

\section{Systems approaches aimed at quantitative and qualitative land evaluation}

Explorative studies on land use often use crop growth models to investigate the potential of a specific land unit. Models for this purpose do not aim for a high accuracy for the individual fields. They should, however, produce reasomably accurate estimates for the specific crop at the specific location under the prevailing weather and management conditions, including water and nutrient management and pest, disease and weed control. Models with time steps of days and with summarizing modules for $\mathrm{CO}_{2}$-assimilation, respiration, water balance, and nutrient uptake are appropriate. The models are applied as part of a procedure used for qualitative and quantitative land evaluation or agroecological zoning (figure 3) (Van Latesteijn and Rabbinge 1994). This procedure was applied in evaluating the possibilities for various forms of land use in the European Community (EC).

In this procedure, the first step was a qualitative land evaluation for units of the soil map that are almost comparable and exposed to the same climate. About 22,000 


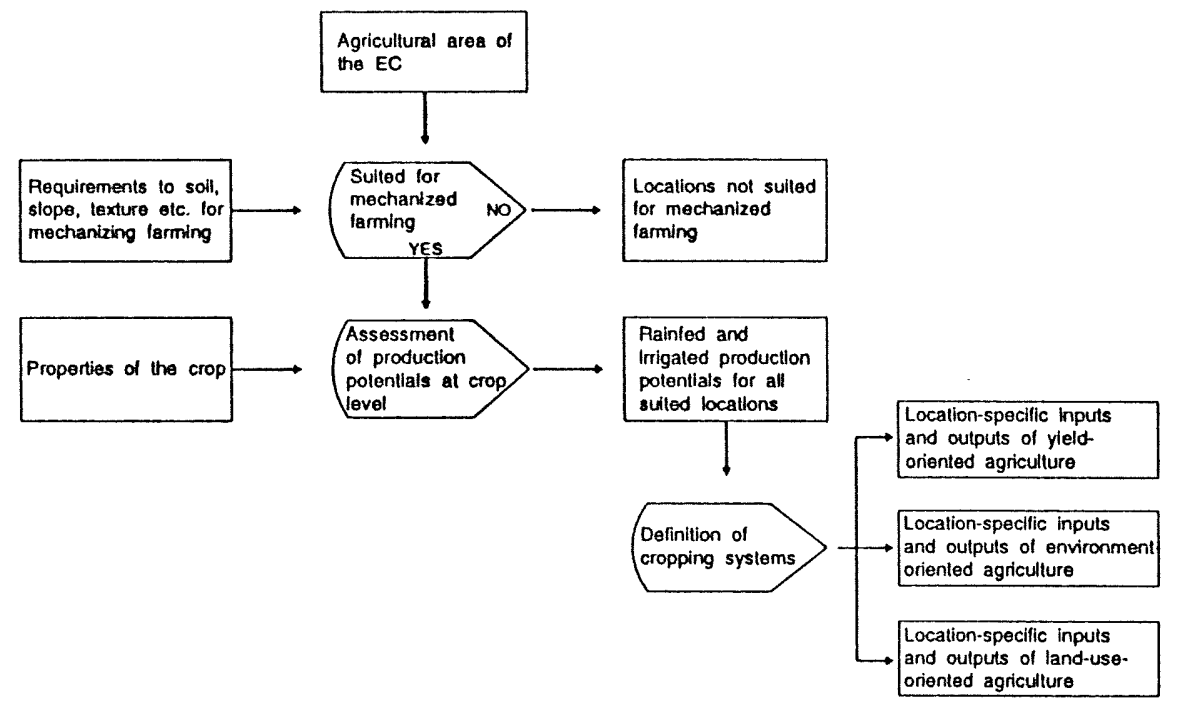

Figure 3. Procedure followed in a land evaluation study for the European Community (Source: Van Latesteijn and Rabbinge 1994)

units are necessary to cover the total area of the EC. The information was derived from a geographic information system (GIS) (Van Latesteijn 1993).

Characteristic factors for these units such as steepness/slopes, salinity, acidity, fractions lutum, and stoniness of the soil are used to make decisions about their suitability for the mechanized farming of grass, cereals, and root crops and their suitability for rough grazings and perennial crops (Van Lanen 1992). The qualitative land evaluation produces an estimate of the percentage of the land that is suitable for certain agricultural purposes. In Greece, for example, only eight percent of the land area is suitable for root crops, 10 percent for cereals, and about 40 percent for grassland. At the other end of the spectrum, Denmark's land area shows a suitability of 85 percent for root crops, 90 percent for cereals and nearly 100 percent for grass production.

Qualitative land evaluation is followed by a quantitative assessment of the growth potentials of crops. This step is carried out with a summary model of crop growth, WOFOST (Van Keulen and Wolf 1986). This simulation model uses as inputs soil data such as water-holding capacity, texture and fertility, climatic characteristics such as temperature and rainfall, and the most relevant crop characteristics such as the phenological, optical, geometrical, and physiological characteristics as assimilation, respiration and partitioning. With the WOFOST model, the rainfed and irrigated yields of winterwheat, maize, sugarbeet, potato, and grass are assessed. In the rainfed situation, the attainable yield is lower than the potential yield, due to water limitation. The limitation due to nutrient supply in combination with water limitation operates in a similar way. Thus, potential and attainable yields may be assessed quantitatively 
for all land units and for various years by running the summary model WOFOST with the prevailing weather data.

These potential and attainable yields are combined in cropping systems that comprise rotation schemes, include certain strategic decisions on cropping system level, and require information on management level and the necessary inputs. Based on results of field experiments, expert judgement, and literature data for a limited set of crop rotations (38) and farming systems (58), technical coefficients representing the relations between inputs and outputs have been derived (De Koning et al. 1992). This land evaluation has resulted in an accurate map of the potential of various crops in various parts of the EC and the inputs needed to attain potential and water-limited yields.

\section{Systems approaches aimed at resource management}

Agriculture that aims at high and efficient productivity has to use external inputs. Overuse and inefficient use of these inputs should be prevented, however. This problem is addressed at the regional level, where decisions have to be made about what land units external inputs are best used, and in what quantities or at which production levels. It has also to be addressed at the lowest aggregation level, where crops can be managed in various production situations and at various production levels, using different production orientations and technologies.

At the crop level, decades of agricultural research have resulted in many so-called dose-effect relations. Dose-effect relations show a "law of diminishing returns" for an individual external input in relation to yield. However, agricultural practice involves a combination of external inputs that, if properly mixed, may result in the law of the optimum (Liebscher 1895). In a sophisticated analysis of agricultural systems using both these laws, De Wit (1992 and 1993) shows the theoretical and empirical basis of his updated and upgraded law of the optimum (figure 4).

From this analysis, De Wit draws the important conclusion that agricultural systems are characterized more by the balanced mix of external inputs than by the simple notion of a law of diminishing returns. Agricultural systems are more complicated than the simple input-output relations characterized by production functions. The implications for resource management on micro and macro levels may be considerable. For example, more extensive, low input systems of production as a way to decrease environmental problems may have an opposite effect, because a drop in productivity is often combined with a loss in efficacy and efficiency of external inputs.

\section{Systems approaches aimed at building a policy agenda}

Explorative studies for long-term options for land use at the supra-regional level may help policy makers make strategic decisions. This is possible by using a methodology developed and illustrated in a study by the Netherlands Scientific Council for 


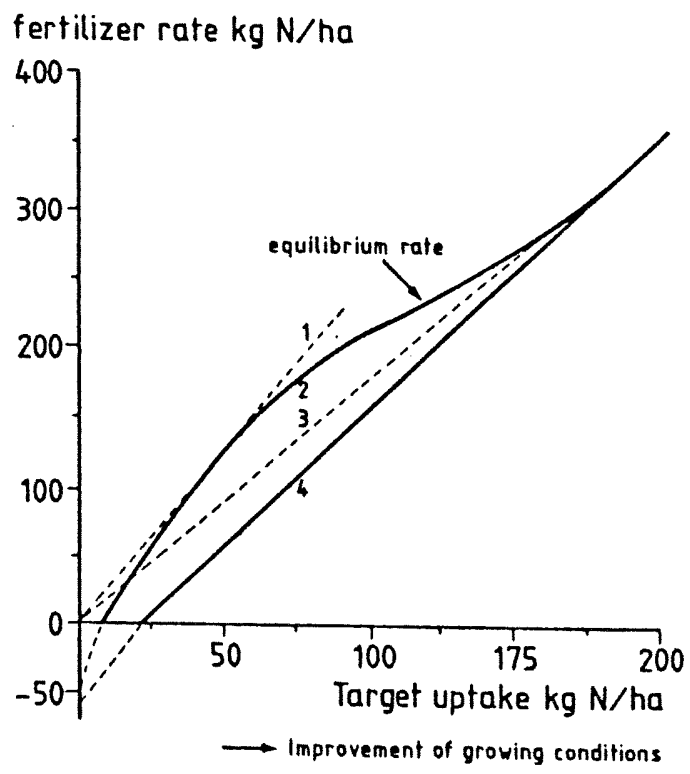

Figure 4. Resource use efficiency, an example of systems approaches. The figure shows the relation between the target nitrogen uptake and the nitrogen fertilization needed in the equilibrium situation to sustain this uptake, in case of concurrent improvement of other growing conditions. Lines 1-4 represent alternative hypotheses (Source: De Wit 1993).

Government Policy on options for future land use in the EC (Netherlands Scientific Council for Government Policy 1992). The methodology is explained in figure 5. The core of the methodology is an interactive multiple-goal model using linear programming techniques.

Land use exemplifies and integrates various objectives considered in this approach. Socioeconomic objectives, ecological, agronomic, and natural objectives may be distinguished. In the GOAL (General Optimal Allocation of Land use) model, eight objective functions that cover these fields have been formulated:

1. maximization of yield per ha;

2. maximization of total labor;

3. maximization of regional labor;

4. minimization of total pesticide use;

5. minimization of pesticide use per ha;

6. minimization of total $\mathrm{N}$-surplus/emission;

7. minimization of $\mathrm{N}$-emission surpluses per ha;

8. minimization of total costs.

These aims reflect the classification into environmental, economic, and social sustainability. To attain environmental sustainability, minimization of pesticide and fertilizer use is essential. Economic sustainability is almost guaranteed if total costs are minimized and if soil productivity continues to rise. Social sustainability can be 


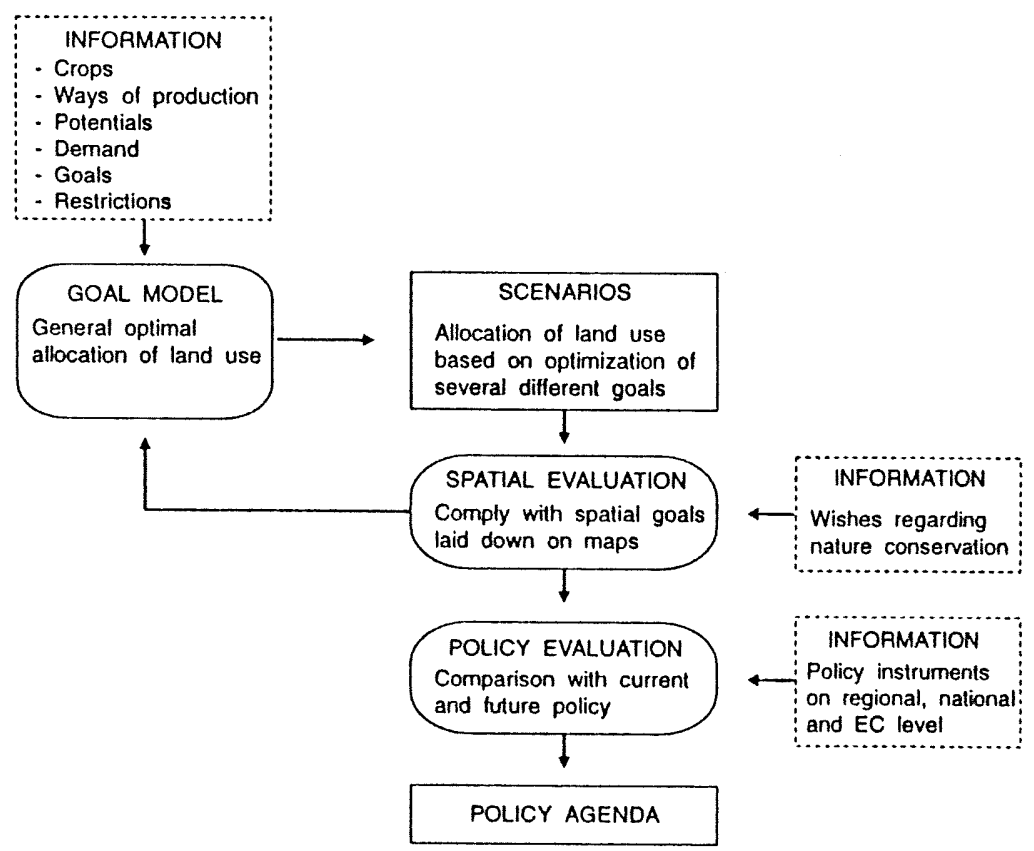

Figure 5. Procedure in Ground for choices, a strategic policy study for rural areas in Europe (Source: Netherlands Scientific Council for Government Policy 1992)

achieved only if labor in the agricultural sector is ensured, or if the available labor is distributed evenly over the regions.

Four scenarios have been developed to represent four contrasting political philosophies about desired policy on land-dependent agriculture and forestry in the EC. A political philosophy here means a coherent set of preferences regarding several aims. All philosophies are based on the assumption that the ultimate aim should be to develop sustainable agriculture and protect the agricultural environment in the rural areas. The various philosophies differ considerably in their views on what must be sustained, however, which clearly illustrates the subjective nature of the concept of sustainability. The four scenarios all represent views on sustainable land use, though from different standpoints.

The following options are distinguished:

- free market;

- regional development;

- nature and landscape;

- environmental prolection.

The scenarios are represented in the GOAL model by setting different preconditions to the objective functions and by varying the demand. Two examples can illustrate this: 
In the free-market scenario, the costs of agricultural production are minimized, while there are no other preconditions to the objectives. Moreover, since free trade permits the import and export of products, the demand for agricultural produce within the EC is modified according to the expectations about new market balances. The model will now choose the most cost-efficient types of land use and allocate them in the most productive regions.

In the environmental-protection scenario, the costs of agricultural production are minimized, but the objective functions include strict limitations as to the use of fertilizers and pesticides. In addition, the demand for agricultural produce is fitted to self-sufficiency. Now the model will choose types of land use and allocations that agree with the imposed preconditions.

With these different options, the model calculates four different scenarios for land use. Policy makers can now see how their priorities will influence land use and how the effects are distributed over the EC. However, concerns about nature and landscape cannot be expressed in figures in ways that the model can interpret. To remedy this, a spatial evaluation is built into the procedure. One map represents the best division of land from the point of view of wildlife protection (Bischoff and Jongman 1993). The map is matched with the regional allocation of types of land use generated by the GOAL model to identify areas that are potentially problematic in terms of competing land use. The results produced by the model may have to be amended as new spatial requirements arise.

Finally, in a policy evaluation, the outcomes are used to decide to what extent current and future policy can cope with the developments in the scenarios. The effort required to achieve the aims can be estimated, depending on whether policy will have to 'go against the tide' or simply go with it. If the outcomes all point in the same direction, there is clearly a conflict between the technical possibilities and the policy, which seeks to achieve something else. In such a case, policy 'goes against the tide'. If the outcomes of the scenarios differ substantially, there is clearly greater scope for policy.

The conflict between technical possibilities and political preferences allows us to identify the extremes of the 'playing field'. Within these boundaries, choices should be made. In the study on the policy options for the rural areas of the EC, the outcomes show much variation among the scenarios. There is ample scope for choice (figure 6). All options differ considerably from the present situation, however. This holds for land use, labor, pesticide use, nutrient surpluses, costs, and regional distribution. The present policy for European rural areas aims at maintaining as much land in agricultural use as possible. This leads to the conclusion that present policies are going against the tide through indirect policies (market and price policies) as well as direct policies (such as structural changes and subsidies related to land use). The conclusion is that current policies are too expensive, environmentally unsound, and agriculturally suboptimal. This implies a clear need for more comprehensive policy
reforms.

Such strategic explorations of policy options may help policy makers in their choices for the long term. Short-term policies should be geared to those long-term 


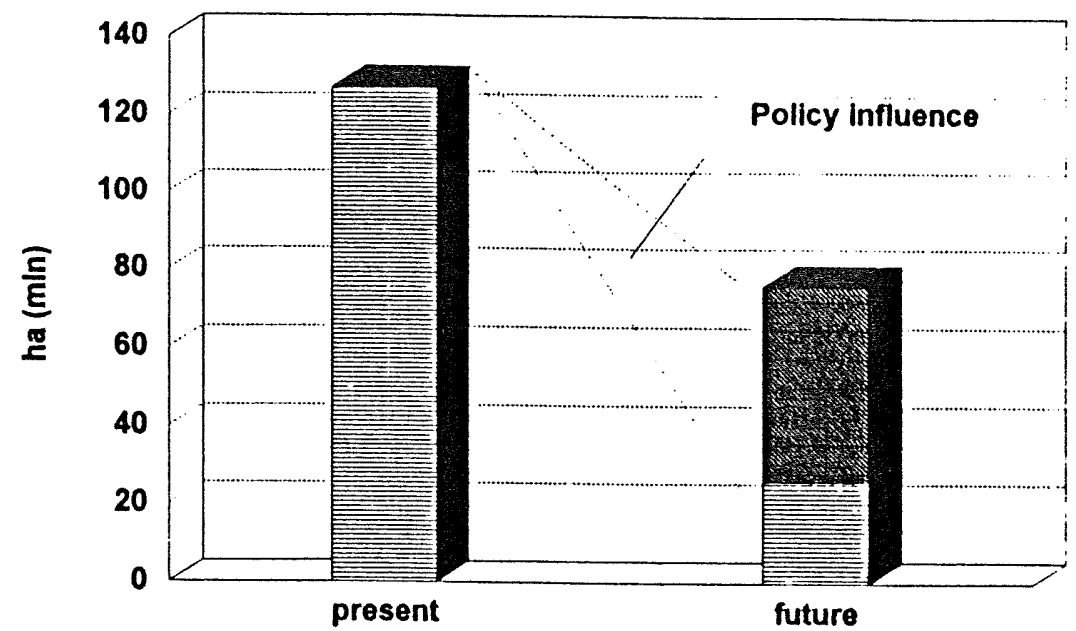

Figure 6. Results of a study on options for land use in the European Conmunity. The two sections in the future land-use bar indicate the minimal area required for sutainable agriculture in the EC and the maximum area needed in alternative scenarios. The large differnce points at ample space for policy influences (Source: Netherlands Scientific Council for Government Policy 1992)

perspectives. This is often not immediately possible due to an institutional and/or cultural indisposition to action. An awareness of perspectives may refute counterproductive policies.

\section{Concluding remarks}

The examples discussed above show how various systems approaches are used to achieve various goals. A scientific goal such as gaining insight requires other tools than evaluating land or exploring policy options. The tools and objectives may be different, but the approach is usually similar.

By clearly stating aims and using a blend of systems analyses, systems synthesis and development of options, systems approaches serve many aims. They may form the backbone of new scientific integrative approaches in agricultural research and land-use studies.

\section{Acronyms}

GIS geographic information system

GOAL general optimal allocation of land use 


\section{References}

Bastiaans $L$ (1993) Understanding yicld reduction in rice duc to leaf blast. PhD thesis, Wageningen Agricultural University, The Netherlands. ISBN 90-5485-166-x, $127 \mathrm{p}$.

Bischoff N T, Jongman R H G (1993) Development of rural areas in Europe: The claim for nature. Netherlands Scientific Council for Government Policy preliminary and background studies V79. Sdu Publishers, The Hague, The Netherlands. $206 \mathrm{p}$.

Van den Bos J, Rabbinge R (1976) Simulation of the fluctuation of the grey larch bud moth. Simulation Monographs. PUDOC, Wageningen, The Netherlands. $91 \mathrm{p}$.

Van Keulen H, Wolf J (Eds.) (1986) Modelling of agricultural production: weather, soils and crops. Simulation Monographs. PUDOC, Wageningen, The Netherlands. 479 p.

De Koning G H J, Jansen H, Van Keulen H (1992) Input and output coefficients of various cropping and livestock systems in the European Communities. Working Documents W62, Netherlands Scientific Council for Government Policy. The Hague, The Netherlands. 71 p.

Van Latesteijn H C (1993) A methodological framework to explore long-term options for land use. Pages 445-455 in Penning de Vries F W T. Teng P and Metselaar K (Eds.) Systems approaches for agricultural development. Kluwer Academic Publishers, Dordrecht. The Netherlands.

Van Latesteijn H C, Rabbinge R (1994) Sustainable land use in the EC: An index of possibilities. In Van Lier H N, Taylor P D (Eds.) Sustainable land use planning. (in press).

Van Lanen H A J (1992) Qualitative and quantitative physical land evaluation: An operational approach. PhD thesis. Wageningen Agricultural University, The Netherlands. $195 \mathrm{p}$.

Leffelaar P A (1986) Dynamics of partial anaerobiosis, denitrification, and water in a soil aggregate. Experimental. Soil Science 142:325-366

Leffelaar P A (1988) Dynamics of partial anaerobiosis, denitrification, and water in a soil aggregate: Simulation. Soil Science 146:427-444.

Liebscher G (1895) Untersuchungen über die Bestimmung des Düngerbedurfnisses der Ackerböden und Kulturpflanzen. Journal für Landwirtschaft 43:49-125.

Netherlands Scientific Council for Government Policy (1992) Ground for choices, four perspectives for the rural areas in the European community, Sdu publishers, The llague, The Netherlands. $144 \mathrm{p}$.

Rabbinge R, Rijsdijk F H (1983) EPIPRE: A disease and pest managenent system for winter wheat, taking account of micrometeorological factors. EPPO Bulletin 13(2):297-305.

Rabbinge R, De Wit CT (1989) Theory of modelling and systems nanagement. Pages 3-15 in Rabbinge R, Ward S A, Van Laar H H (Eds.) Sinulation and systems management in crop protection. Simulation Monographs 32. PUDOC, Wageningen, The Netherlands.

Van Roermund H J W, Van Lenteren J C (1994) Simulation of the population dy namics of the greenhouse whitefly and the parasitoid Encarsia formosa on tomato. (in prep).

De Wit C T (1968) Theorie en model. H. Veenman \& Zonen NV, Wageningen. 13 pp.

De Wit C T (1982) Coordination of models. Pages 26-31 in Van Laar H H; l'enning de Vries F W T (eds.) Simulation of plant growth and crop production. Simulation Monographs. PUDOC, Wageningen, The
Netherlands.

De Wit C T (1992) Resource use efficiency in agriculture. Agricultural Systems 40:125-15I.

De Wit CT (1993) Resources use analysis in agriculture: A struggle for interdisciplinarity. Key note address prepared for 'The future of the land', Symposium, 22-25 August 1993, Wageningen, The Netherlands. 